\title{
Ethical and social issues of 'teleservices' for disabled and elderly people
}

\author{
Julio G. Abascal \\ Informatika Fakultatea, Euskal Herriko Unibertsitatea, \\ Basque Country, 649 postakutxa, E-20080 Donostia, Spain \\ Tel.: + 3443 218000. Fax: + 3443219306 \\ Email: julio@si.ehu.es
}

\begin{abstract}
In recent years the implantation of 'teleservices' as an alternative for the social integration of people with disabilities and elderly people has been observed. Telematic services such as teleteaching, telework, teleshopping, telecare, telesurveillance, teleleisure appear to be the panacea for the complete social and labour integration in developed countries. In this paper some aspects related to ethical and social issues of teleservice proposals are studied. Other matters in question, such as technical feasibility (which is not always evident) or economic profitability (for a very high anticipated cost), are not discussed here. As a conclusion, a list of conditions for every project of implementation of teleservices for disabled and/or elderly people is proposed.
\end{abstract}

\section{INTRODUCTION}

The development of telecommunications, from the telegraph to broadband networks, has promoted crucial changes in human relationships, maybe without precedent in human history. Similarly, the diffusion of computers has caused a big impact in the life of the citizens of developed countries. But the combination of both information technology and communication has resulted in another technology, telematics, with a social action that goes much further than its direct components. It is foreseen that the diffusion of telecommunications will allow in the short term the apparition of new services offered from remote computers connected to telematic networks. Some of these services are already active, while 
others are only proposals of intentions sometimes without a complete specification. Even if nowadays telematic services are aimed at every kind of user, it is said that some of these services were originally proposed to alleviate the problems, such as social and labour integration, of disabled and elderly people. In the next section certain teleservices are explained briefly.

\section{TELEMATIC SERVICES FOR DISABLED AND ELDERLY PEOPLE ${ }^{1}$}

From the time of the industrial revolution, family relationships have notably changed in industrialized countries. The extended family, including grandparents, aunts and uncles, parents and children living in the same house, has evolved to a nuclear family including only parents and children until the latter become independent. In many cases, modern houses and flats are not conceived for big families and the lack of adequate space for the elderly restricts their integration. Thus, grandparents and single or widowed relatives who used to find a place in the extended family must now live on their own. Other alternatives, such as residential institutions, are nowadays being abandoned. This possibility is only considered adequate for people with special needs due to mental or physical diseases. The emergent alternative is the development of technologies that allow elderly people to live on their own with the highest comfort and the minimum risk.

A similar analysis can be made of the social situation of people with disabilities. The conclusion can also be the convenience of telematic services to help them to experience a more autonomous life.

Even if some of these teleservices lack an accurate specification, I will try to describe some of them superficially in order to analyze their impact.

- Telealarm. The user is equipped with a device that automatically or manually generates a call to a remote surveillance centre when he or she suffers an emergency due to an accident, disease, security problem, etc. ${ }^{2}$. Different ways to operate this service (with and without family participation) and diverse technical support are being tested (telephone ${ }^{3}$, text telephone, video-telephone, interactive television).

- Telecare is proposed as a distant medical attendance service. In some cases care is limited to health advice by means of speech or/and written communication ${ }^{4}$. More complex systems may include teleexploration, and diagnostic and therapeutic advice. Remote patient monitoring and transmission of physiological signs may be required in this case.

- Teleinformation services offer elderly people valuable information about diverse aspects of ordinary life: public transport, emergency telephone numbers, relatives' addresses, etc. In some cases they may include advice about everyday tasks, developing and agenda planning (schedule for medical treatment, doctor's appointments, and special days like birthdays, holidays).

- Different kinds of interpersonal telecommunication services (that can include speech, image and text transmission like video-telephone ${ }^{5}$, telefax, or electronic mail) have been tested to decrease the isolation of disabled people. When elderly people lack these services, they tend to use alarm systems to simply 'speak with somebody'. 
- There exist proposals for diverse services that can be included in the teleleisure section. They may include information about sports, hobbies, and culture.

- Services like teleshopping have been extensively promoted and do not need any more explanation.

In addition, there exist some telematic services specially intended for people with severe motor restrictions that may impede their access to places where various activities are usually developed. It is said that telework and teleteaching were first conceived for disabled people, but people with other kind of restrictions (for example, people living in very isolated villages) can also profit from these services.

- Telework offers the possibility of carrying out remunerated work from home using a personal computer and telematic communication, usually via a telephone network ${ }^{6}$.

- Teleteaching offers different levels of distance education using computer-aided instruction via telematic networks in addition to the usual remote teaching methods.

It is important to mention that these telematic services for disabled and elderly people are highly conditioned to the availability of human-computer interfaces well adapted to the physical and cognitive characteristics of users. Even though there are several interesting projects in progress in this area, the problem is not yet adequately solved in many cases.

\section{WEAK POINTS OF TELESERVICES}

\section{Competence, technology acceptability and user needs}

In advanced societies it is frequently assumed that the introduction of telematic services will by themselves result in the integration and the happiness of disabled and elderly people ${ }^{8}$. But, even if technological advances enhance the quality of life of this population, there are two important factors that can miscarry this objective: the lack of ability of the hypothetical users to handle complex devices, and also the acceptability of the services .

There exists an open discussion about the low level of technology acceptance by elderly people. Rejection is frequently due to the low quality of the interface: automatic cashiers (or automatic teller machines) are a paradigmatic example. Moreover, some studies show that adequately trained elderly people are in general able to use technology ${ }^{10}$. In addition, it is expected that the acceptance of technology by elderly people will increase with the ageing of people accustomed to technology.

Another possible cause of the rejection of telematic help systems can originate in a deficient evaluation of user needs. Frequently, the emergence of new technological advances moves engineers to imagine hypothetical benefits for disabled and/or elderly people if these technologies were to be applied to solve assumed user needs ${ }^{11}$. These assumptions, when they are not based on in-depth studies about users' interests, needs, wishes, and likes lead to misconceptions that produce systems unsuited to the target user group and hence they are rejected. Only 
serious studies about user needs ${ }^{12}$ can result in systems that truly satisfy these needs and therefore have the possibility of being accepted by users.

\section{Technology for human contact}

The introduction of technology to allow elderly and disabled people to be more autonomous and socially productive may lead to the substitution of human relationships for technology; frequently it is easier for families to pay for devices than to dedicate time to personal relationships. This same scheme can be reproduced at the social level: institutions may prefer to create telematic services than to maintain traditional social and care services.

To avoid this possibility, it is convenient to verify that proposals for the provision of telematic services do not lead to the restriction of personal contact or the elimination of other non-technology based services.

\section{Privacy and freedom}

Advances in global positioning systems (GPS) technology, satellite communications, sensor technology and so on, allow the existence of teleservices which include systems registering data about the geographic position of the patient or his/her vital signs and sending them to a remote surveillance centre. This centre is immediately informed about any danger or change in the user's situation. Thus, telesurveillance allows chronically ill patients, who would usually be hospitalized, to live at home.

The idea seems to be very attractive but one cannot forget that these systems can interfere with the capacity of patients to make their own decisions (like deciding not to obey medical prescriptions if they wish). Even if some patients would prefer to be under telematic surveillance at home rather than to remain in hospital for long periods of time, this alternative can be inadequate in other cases. So, people living alone or without a serious pathology can be compelled to accept these services under family or social pressure. In addition, the proliferation of these kinds of devices can lead to a socially accepted 'watched freedom'. While some countries are regulating the use such devices, the majority lack laws to protect patients' rights from the excesses produced by technology ${ }^{13}$.

\section{Labour integration}

Telework is one of the more promoted teleservices. This telematic service offers the worker the possibility of developing his/her work from a remote site (usually from home), thereby avoiding unnecessary commuting. From the point of view of the company, telework also offers advantages: among them, the possibility of using contractors for short periods of time or to carry out particular tasks. In addition, there is no need for space for workers (in some cases arriving at the 'virtual company' concept).

In fact, telework is an interesting alternative not only for people with disabilities. Currently, telework is open to able-bodied people to carry out diverse activities that do not require a worker's physical presence in the company. This profusion of telework jobs poses several social problems that are not going to be 
treated here, including the unsteadiness of contracts, excessively long working timetables, and labour rights ${ }^{14}$.

Users with severe movement restrictions, who make up a large percentage of the disabled population, are very interested in telework because of their difficulty in accessing companies' premises. But they also find difficulties in using computers. The majority of people with disabilities wanting access to telework have mobility restrictions that make the use of standard interfaces (screen-keyboard-mouse based) difficult. So, these people require special interfaces that usually produce slower communication rates. Even though promising work is in progress trying to enhance communication speeds (by means of special keyboards, word prediction systems, and so on), nowadays the communication rate attained by people with severe movement restrictions remains too slow to be competitive in a production environment.

Nevertheless, the major problem for people with disabilities considering telework is the possibility of enlarging their isolation. One cannot forget that the desire of people with disabilities to access the labour market is related to their need to integrate into productive society as a 'full member' (obtaining resources to become autonomous and self-confident), but it is also motivated by the need to get in touch with people other than their families and therapists. From this point of view, telework can become a solution to the problem of obtaining a job. But the possibility of accessing only the productive part of the labour activity exists, while remaining outside the socialization that accompanies the working environment.

It has been said that telework is a good way of integrating disabled people because it does not differentiate between disabled and able-bodied people. However, what kind of 'integration' is possible when there is an interposed telematic network that hides the fact that, on the other side, there is a person who is 'different'? In addition, if telework becomes an extensively used service, competition among the disabled and non-disabled may become imbalanced because of the productivity question. As a result, people with disabilities may again be relegated from the labour market.

\section{HIDDEN MOTIVATIONS FOR THE IMPLANTATION OF TELESERVICES}

Sometimes the planning, development and implementation of teleservices are based on different motives than those mentioned. To understand that there can be other reasons for implementing teleservices, one cannot forget that the disabled and elderly populations have in general low economic power that results in a not very attractive market for business ${ }^{15}$.

Let us analyze three of these possible 'occult' motivations, that are easily detectable in some teleservices projects.

\section{a. The availability of the technology}

Experience frequently reveals that the only justification for backing projects related to telematics for disabled and elderly people is the availability of the necessary technology. These 'advances' are justified by themselves without any study of needs, feasibility, cost/benefit, social impact, and so on ${ }^{16}$. 


\section{$b$. The use of the disability flag to obtain funding for general purpose projects}

Some companies have found, in the provision of telematic services to disabled and elderly people, a way to open up a broader market. In this way, funding obtained to develop services for disabled and elderly people is sometimes used to carry on projects destined for a wider population where disabled people are only a small proportion. This explains the lack of adequate evaluation of user needs: teleservices are not actually devoted to disabled and elderly users.

\section{c. The use of the disabled and elderly population to test services intended for a broader population}

In connection with the previous point, these projects can be used not only to obtain funding for services that are really for the general public, but also to test their market perspectives, feasibility, acceptability, and so on.

\section{ANOTHER APPROACH TO TELESERVICES}

\section{'Disintegration' and compensatory measures}

If teleservices became a massively applied solution for disabled and elderly people in the future, they could produce loneliness and social disintegration. The possibility of carrying out the majority of everyday tasks (work, study, leisure, and communication) from home may inhibit socialization and human contact. Let us look at an example. If a student with a severe physical handicap wants to attend a university course, it is necessary to carry out work to eliminate the architectural barriers present in the majority of old buildings. But, increasingly, people wanting to sign up for degree courses are directed to universities that give their courses remotely (distant universities) through teleteaching services. In this way, the existence of this telematic service may become an excuse not to face the expenditure of making every university building accessible. The distant university is a legitimate alternative for every student (disabled or not) if he or she wants it. But if it is the only way for disabled people to access higher studies this imposition results in being discriminatory with respect to the other citizens.

A similar situation may be caused by the introduction of telework as a solution for disabled people, because it may instigate the disappearance or the reduction of existing integration measures (like laws existing in some countries that force companies over a certain number of workers to employ disabled people).

Thus, it is evident that compensatory measures are needed to avoid the disintegration effect that can result from the introduction of some teleservices.

\section{Telematic services and evaluation of the technology}

The cliché, 'every scientific advancement and hence its technological application is good' frequently impedes a deeper evaluation of the technology. For this reason, it 
is very difficult to find rigorous studies about the social impact of teleservices in the target population and its environment ${ }^{17}$.

The request for an evaluation of telematic services for disabled and elderly people is frequently opposed using the following arguments ${ }^{18}$.

1. 'If you are against current technology you want to go back to the Stone Age,"

2. 'If there is a need for corrective measures, they must be provided by the administration'.

In relation to the first point, the dilemma cannot be posed as 'technology or nothing'. The aim is 'technology with the necessary complementary measures'. In the case that concerns us, elderly or disabled people must receive guarantees that the implementation of telematic services will not have a negative influence on their social integration.

\section{The model of contaminant industry}

With respect to the second argument, it is accepted that some corrective measures are necessary but they are left to the administration. Following this model, while the agent that uses the technology obtains the benefits, the administration, on behalf of all the population (with its money) must bear the expense of compensating for the damage. This has been the procedure frequently used by contaminating industries. Continuing with this example, the emergent proposal for this problem is to ask the contaminating agent to establish systems in a way that avoids contamination (or to pay for it). In the case of telematic services the designer of the teleservice (that is, the potential social disintegrator) should create the necessary compensatory measures to avoid disintegration. It is also fundamental that these measures are included in the implementation plans of the teleservice.

\section{Conditions for teleservices}

From the analysis of the potential impact of teleservices in the target population and its environment, the need for some corrective measures and guarantees has been stated in this paper. In summary: in order to prevent the above mentioned problems and dangers from arising, telematic services for disabled and elderly people must fulfil the following conditions:

- be based on rigorous studies of user needs

- avoid the 'substitution of human contact for teleservices'

- respect the freedom and the privacy of the user, taking into account the ethical aspects

- avoid the experimentation of new services with elderly and disabled people

- include the necessary socializing measures to compensate the tendency to loneliness.

To become effective, these conditions should be supported by social awareness of the potential dangers of teleservices if they are applied massively without control. While the legal regulation of some aspects of teleservices is active in a small number of countries ${ }^{20}$, greater efforts in developing laws that protect the disabled and elderly as potential users of teleservices are necessary. 


\section{CONCLUSIONS}

As has been previously outlined, industrialized society tends to isolate disabled and elderly people. To overcome this problem, some telematic services have been proposed as a way to promote the social and labour integration and to enhance the autonomy, quality of life and security of both disabled and elderly people.

In this paper the real motivation behind some of these proposals has been discussed. The need to avoid damaging effects on the user population has been emphasized. From this point of view, this paper suggests a list of conditions that should be required for all implantation projects of new telematic services for disabled and elderly people, to ensure that their implementation is carried out with enough guarantees for the users. Obviously these conditions require a larger development, and legal and social support to guarantee their application and effectiveness.

\section{REFERENCES}

(Augustsson-91) L. Augustsson. Access to the USA - Recent Disability Legislation. The Swedish Handicap Institute, 1991.

(CE-88) Council of Europe. Legislation on the Rehabilitation of Disabled People. Strasbourg, 1988.

(Edwards-95) Alistair D.N. Edwards (Ed.). Extra-Ordinary Human-Computer Interaction. Interfaces for Users with Disabilities. Cambridge University Press, Cambridge, 1995.

(Hypponen-96) H. Hypponnen (Ed.). Future Actions in the Field of Telematics and Disabilities. COST 219. CEC-DGXIII (EUCO-TELE 219/CTD/96). Finland, 1996.

(IHAC-95) Information Highway Advisory Council. Connection Community Content. The Challenge of the Information Highway. Final Report of the IHAC. Minister of Supply and Services. Canada, 1995.

(Pereira-94) L. M. Pereira and J. I. Lindström (Eds.). Videotelephony for Disabled and Elderly People. COST 219. CEC-DGXIII (EUCO-TELE 219/CTD/94). Lisbon, 1994.

(Roe-95) P. R. W. Roe (Ed.). Telecommunications for all. COST 219. CEC-DGXIII. Luxembourg, 1995.

(Sanmartín-90) J. Sanmartín. Tecnologia y futuro humano. Anthropos, 1990.

(Taipale-95) V. Taipale and L. M. Pereira. The Social Aspects of Telematics, Disabled and Elderly People and The Future Challenges. In (Roe-95)

(Tapiovaara-95) P. Tapiovaara (Ed.). Services for Independent Living. COST 219. CEC-DGXIII (EUCO-TELE 219/CTD/95). Finland, 1995.

(Tetzchner-91) S. von Tetzchner (Ed.). Issues in Telecommunication and Disability. COST 219. CECDGXIII (EUR 13845 EN). Brussels, 1991.

(Thakkar-90) U. Thakkar. 'Ethics in the Design of Human-Computer Interfaces for the Disabled'. ACM SIGCAPH Newsletter, No. 42 June 1990.

\section{ACKNOWLEDGEMENTS}

Many thanks to the colleagues, including the referees, who have made comments, suggestions, and corrections to the multiple previous versions of this paper.

1 The association of disabled people and elderly people (sometimes under the denomination of people with special needs) is frequently rejected because both communities often present different characteristics and needs. This association, which is very common in institutional, social, and research and development programmes, is due to the intention to apply the same technical solutions to both populations. 
See Emergency Services and Alarm Systems by J. I. Lindstrom and M. Martin (Roe-95).
See, for instance, M. Martin, Emergency Telephones (Tetzchner-91).
See, for instance, M. Gauci, The Provision of Care [in Malta] Through the Telecare Service
(Hyppönen-96).
See (Pereira-94).
See Telework as an Employment Option for People with Disabilities by B. Murray and S. Kenny
(Tetzchner-91).
See, for instance (Edwards-95).
This idea is very similar to the 'technologic determinism' concept (Sanmartin-90).
See C. Rott, Elderly people and new technology: Psychological issues of competence and
assistance (Tapiovaara-95).

Attitudes and Acceptance by S. Bjfrneby et al. (Tetzchner-91) refutes the myth of the technological incompetence and disinterest of elderly and disabled people in using technology through experiments carried out in England, Portugal, and Norway.

11 Designers of input devices for interfaces should integrate disabled user needs as an integral part in their designs (Thakkar-90).

12 Such as the study mentioned by $\mathrm{S}$. Collins et al. in Telecommunications Needs as Expressed by Elderly People and People with Disabilities (Tetzchner-91).

13 With respect, the innocence showed by engineers in relation to ethical problems resulting from technological applications turns out to be very curious, to say the least. The cliché used by scientists is 'technologies are neutral by themselves' (Sanmartín-90).

14 Some of the ethical and social questions posed by telework are considered in the interesting Appendix IV of the report entitled Connection Community Content. The Challenge of the Information Highway. Final Report of the Information Highway Advisory Council (IHAC-95), where the representative of the Canadian Labour Congress in the Advisory Council explains his opinion about the impact of telework on employment and in the workplace.

15 But they can become an interesting potential market in the opinion of M. Martin, People with Special Needs as a Market (Tetzchner-91).

16 This behaviour is based on two very common assumptions in the area of science/technology: 'the application of the technology always supposes an advancement' and 'the availability of the technology is the only requirement for its application'. J Sanmartin calls technologic imperative the tendency to accept, in the name of human progress, that 'all the things that are technically feasible must be done'. He identifies this idea as one of the commonplaces of industrialised society. Following this philosophy, 'the innovation will be beneficial if we ensure that the conditions for its application are the correct ones' (Sanmartín-90).

17 Evaluation of the technology before its application is hardly accepted by scientists and engineers. Even if, nowadays, it is generally recognised that, for instance, the use of nuclear technology should have been evaluated before its extensive implantation, people are reluctant to evaluate other emerging technologies, such as genetic engineering, that pose ethical questions. This social resistance to the evaluation of technology may come from the false idea that criticism can destroy one of the pillars of the technologically developed and supported society.

18 These arguments are in fact very similar to the ones used when doubts and criticisms are shown in relation to the implantation of some other technologies that are arising.

19 (Sanmartín-90).

20 Information about existing legislation in Europe can be found in these volumes (CE-88; Augustsson-91). 